\title{
$\underline{\mathrm{O} J \mathrm{ED}}$
}

Volume 5, Issue 1 (2020), pp. 160-166

International Journal of

Multidisciplinary Perspectives in Higher Education

ISSN: 2474-2546 Print/ ISSN: 2474-2554 Online

https://ojed.org/jimphe

\section{Remote Engineering Education Under COVID-19 Pandemic Environment}

\author{
John Jongho Park, Mihee Park, Kathy Jackson, and Garrett Vanhoy \\ Penn State University/U.S.A. and University of Maryland/U.S.A.
}

\begin{abstract}
As a result of the sudden onset of the COVID-19 pandemic, engineering curriculums that were taught in-person for decades were forcibly transitioned into a remote-learning environment in such a short time that instructors and students alike could not adequately consider how to replicate the efficacy and efficiency of in-person learning to the remote learning environment. In this essay, the problem of effective replication is studied from the perspective of emotional experiences that lead to effective learning. Through this review, the authors hope to enlighten instructors and students about simple and effective practices that can be implemented in this harsh environment and to mitigate the effect that COVID-19 will inevitably have on the effectiveness and enrollment of engineering undergraduate curriculums.
\end{abstract}

Keywords: COVID-19, online education, engineering education, emotional experiences

During the COVID-19 pandemic, engineering courses in the U.S. were redesigned for a remote-learning environment. This transition was difficult considering the necessity of significant lab courses for engineering curriculums to teach online, the lack of resources for instructors to successfully transition a course to a remote-learning environment, and student's unfamiliarity with a remote-learning environment. It is challenging to deliver lab courses, a core part of undergraduate engineering curriculums 
required by the Accreditation Board for Engineering and Technology (ABET) for program accreditation, in a remote-learning environment.

While there are many challenges in making effective lab courses, even for in-person learning environments, some programs have started to offer purely remote-learning environments in recent years. The few ABETaccredited undergraduate engineering programs that have fully remote offerings have developed such a program through a phased approach over several years with significant up-front financial and human-resource investment from the universities or have kept their respective programs to a small handful of participants (e.g., Penn State University, B.S. Electrical Engineering online program). As a result of the circumstances and uncertainty brought about by COVID-19, engineering curriculums have adapted a core part of their curriculum abruptly which results in profound effects on the academic development of engineering undergraduates for years to come.

Considering the suddenness and lack of preparedness, it is not unreasonable to expect that at least for some students, strong negative emotions may have arose as they adjusted to the hurried and unfamiliar learning situation during these unpredictable times. These students' unprecedented learning experiences could have been exacerbated by academic stress and other stress factors such as reduced face-to-face social interactions, limited networking with college personnel (faculty, staff, and peers), longer response time for communication via e-mail or other online platforms, and extended hours of screen time (Adnan \& Anwar, 2020).

It is possible that this current change in delivery of engineering coursework will have substantial long-term effects on engineering students, and the increase in psychological stressors may lead to substantial increases in disengagement with lectures and other instructional activities. In other words, the continuation of these instructional changes may cause substantially increased stress levels for students that ultimately impact wellbeing, academic emotions, and college retention (Heo \& Han, 2018; Muljana \& Luo, 2019; Ramo et al., 2020).

Therefore, the success of engineering education for both the near and long-term future depends on providing students a positive learning experience during the establishment of this new normal of remote engineering education. It is imperative for engineering educators to understand students' learning experiences associated with academic emotions during online education in order to support and maintain students' learning and academic performance. Thus, it is urgent to understand online technical engineering education where engineering educators are rapidly responding to the global COVID-19 pandemic.

Engineering students, like others in STEM disciplines, often take challenging courses that involve problem-solving, working with others, and 
hands-on labs. A national survey conducted at the end of Spring 2020's semester surveyed students' experiences in STEM courses. Although fewer than half of students expressed dissatisfaction with their learning after their courses went online, students' open-ended responses to their greatest challenges indicate they have issues with staying motivated without the structure of a class routine, they miss the presence of their instructors and peers, and the loss of authentic, hands-on experiences makes learning more difficult (Means \& Neisler, 2020).

The abrupt change to remote learning has impacted students and while some findings suggest that students did quickly adjust and are continuing to do well with this new technology-delivered instruction, there are also students who report they are struggling and feeling disengaged (Ramo et al., 2020). The remainder of this essay addresses the significance of engineering students' challenges and needs during online engineering instruction by reviewing the evidence of factors that make for more efficient, effective remote and online instructional practices. The discussion may also apply more widely to other disciplines involved in remote education.

\section{Proposed Remedies through Analysis of Emotional Factors}

The emotional experiences of students that are identified as "academic emotions" is a topic of interest because they delineate normal emotional experiences from those that directly link to academic learning, instruction, and achievement (Pekrun et al., 2002). The literature on academic emotions within the field of educational research and its application to online education informed by the instructional design acknowledges the importance of emotional regulation as well as instructional strategies in online engineering education.

Emotions influence a wide range of cognitive and motivational processes such as perception, attention, learning, decision-making, and problem-solving. A sense of lack of control or a negative learning experience is likely to produce negative emotions such as anger, anxiety, hopelessness, shame, or boredom (Pekrun \& Stephens, 2009). They addressed classroom activities and school achievement situations that are associated with students' emotions. Pekrun's academic emotions could be applied usefully to remote instruction of engineering by explaining the emotional experience associated with learning in a remote-learning environment.

During this pandemic, we can assume that engineering students are experiencing various emotions, both positive and negative, that are related to various aspects of remote instructional activities, communication with instructors, and interactions with peers. Because most engineering courses were developed and delivered offline before the pandemic, there is a high 
chance that the shift to online platforms resulted in students experiencing various challenges that can result in negative emotions.

In a preliminary study of engineering students' mental health and wellness, Danowitz and Beddoes (2018) found that engineering students suffer certain mental health issues at a higher rate than other US students. They reported that intense negative emotions discourage individuals from being engaged in learning and we should consider that engineering students may experience disengagement and amotivation with the shift to remote engineering courses. In addition, Lee and Adam (2016) investigated the three aspects of negative emotions (e.g., stress, anxiety, and depression) on engineering students. The authors reported cognitive interventions such as the openness mindset and positive thinking will reduce students' negative emotions. In addition, Kim and Hodges (2012) studied college students' emotions, motivation, and achievement in an online remedial math course, and whether a brief intervention focused on emotion regulation would significantly improve the treatment group's learning outcomes. Results indicated the intervention helped students maintain positive emotions such as enjoyment and pride during their learning, which increased their motivation and engagement, though not their actual achievement relative to control group students. This study suggests that the idea of interventions for students to regulate emotional arousal will eventually enhance their learning.

Further, Angelaki and Mavroidis (2013) investigated the role of emotions in an online distance learning program for students who were new to online learning. These learners frequently expressed various emotions, both positive and negative, during their online learning experiences. The authors reported students' interactions with all components of the program as forming an "emotional climate" that influenced students' learning. Results showed that a positive emotional climate, created in part by positive social relationships with their instructor and fellow learners, mitigated the negative emotional arousals. Additionally, Tempelaar et al. (2012) showed that positive emotions such as enjoyment and happiness contributed to effective learning in an online statistics course, and negative emotions such as boredom and hopelessness were a significant hindrance for online learning compared to face-to-face learning environments.

Severe acute respiratory syndrome (SARS) resulted in an infectious spread that prompted educators to experiment with pedagogical approaches within the teaching and learning of science and engineering courses. Due to SARS, Low et al. (2006) investigated the teaching of science and engineering courses in virtual laboratory settings by utilizing the MATLABbased QUANSER training kit at the SIM University (UniSIM). They reported a virtual laboratory environment that effectively allowed students to interact with a remotely set up ECG measurement system at the UniSIM Bioelectronics Laboratory. 


\section{Conclusion}

Although it is more relevant to engage this research with online engineering education, it has not yet been fully mined for its insights about the particular emotional and learning experience of engineering students in the novel and suddenly implemented remote learning and online learning environments resulting from the pandemic. In addition, they reported that online learning environments demand learners to be more self-motivated and self-regulated in order to have similar learning outcomes to face-to-face settings. Lehman et al. (2012) claimed that the nature of computer-mediated learning environments often triggers confusion in learners as they encounter technical difficulties and program-based obstacles. Interestingly, they reported that negative emotions can be beneficial to eliciting states of cognitive disequilibrium. Given the heavily hands-on, team-based, and activity-based courses that are characteristic of the engineering undergraduate curriculum, the emotional challenges students are facing need further investigation.

In conclusion, the contagion and virulence of COVID-19 has impacted the world and all aspects of education which resulted in drastic sanitizing and social distancing. Whether individuals are on the front lines or working from home, the entire world is struggling to adjust to the new normal and envisioning an uncertain future. Technological adaptations have emerged, for example, online social gatherings and virtual meetings, but it is not clear what long-term educational plans and adaptations will need to be made. As an education community, we have a particular role and responsibility to design, implement and evaluate this transition. How best to address the academic intellectual and emotional needs of engineering students must be considered when designing new instructional practices. This essay intended to provide insights about online education and students' emotional experiences with the goal of helping both students and instructors. Ultimately, as educators, we should ensure that we continuously provide quality education and share this vision with students so that they can envision and pursue a just society and build a more resilient worldwide community during this unprecedented pandemic time.

\section{References}

Adnan, M., \& Anwar, K. (2020). Online Learning amid the COVID-19

Pandemic: Students' Perspectives. Online Submission, 2(1), 45-51.

Angelaki, C., \& Mavroidis, I. (2013). Communication and Social Presence:

The Impact on Adult Learners' Emotions in Distance Learning.

European Journal of Open, Distance and e-Learning, 16(1), 78-93.

Danowitz, A., Beddoes, K. (2018, April). Characterizing Mental Health and

Wellness in Students Across Engineering Diciplines. Paper

presented at 2018 CoNECD - The Collaborative Network for 
Engineering and Computing Diversity Conference, Crystal City, Virginia, https://peer.asee.org/29522

Heo, J., \& Han, S. (2018). Effects of motivation, academic stress and age in predicting self-directed learning readiness (SDLR): Focused on online college students. Education and Information Technologies, 23(1), 61-71.

Kim, C., \& Hodges, C. B. (2012). Effects of an emotion control treatment on academic emotions, motivation and achievement in an online mathematics course. Instructional Science, 40(1), 173-192.

Lee, M. F., \& Adam, W. W. (2016, December). A comparison study of methods to solve the mental health problem between the engineering and non-engineering students. Paper presented at 2016 IEEE International Conference on Industrial Engineering and Engineering Management (IEEM), Bali, Indonesia. doi: 10.1109/IEEM.2016.7797860

Lee, M. F., \& Ahmad, R. J. (2014, December). Mind matters: an approach to increase understanding of mental illness among the engineering students. Paper presented at 2014 International Integrated Engineering Summit (IIES 2014), Universiti Tun Hussein Onn Malaysia, Johor.

Lehman, B., D'Mello, S., \& Graesser, A. (2012). Confusion and complex learning during interactions with computer learning environments. The Internet and Higher Education, 15(3), 184-194.

Low, S., Low W. P., Chuah C. K. (2006). A Novel method to teach Science and Engineering in a Virtual Laboratory Environment with flexible learning. In PhilipTsang, Reggie Kwan, \& Robert Fox (Eds), Enhancing Learning through Technology (pp. 124-135).

Singapore: World Scientific Publishing.

Means, B., \& Neisler, J. (2020). Suddenly online: a national survey of undergraduates during the COVID-19 pandemic. Digital Promise, San Mateo, CA.

Pekrun, R., Goetz, T., Titz, W., \& Perry, R. P. (2002). Academic emotions in students' self-regulated learning and achievement: A program of qualitative and quantitative research. Educational psychologist, 37(2), 91-105.

Muljana, P. S., \& Luo, T. (2019). Factors contributing to student retention in online learning and recommended strategies for improvement: A systematic literature review. Journal of Information Technology Education: Research, 18, 19-57. doi:10.28945/4182

Pekrun, R., \& Stephens, E. J. (2009). Goals, emotions, and emotion regulation: Perspectives of the control-value theory. Human Development, 52(6), 357-365.

Ramachandran, R., \& Rodriguez, M. C. (2020). Student Perspectives on Remote Learning in a Large Organic Chemistry Lecture Course. 
Journal of Chemical Education, 97 (9), 2565-2572. doi:

10.1021/acs.jchemed.0c00572

Ramo, N. L., Hald, E. S., \& Huang-Saad, A. (2020). Synchronous vs.

asynchronous vs. blended remote delivery of introduction to

biomechanics course. Biomedical Engineering Education, 1-6. doi:

10.1007/s43683-020-00009-w

Tempelaar, D. T., Niculescu, A., Rienties, B., Gijselaers, W. H., \& Giesbers, B. (2012). How achievement emotions impact students' decisions for online learning, and what precedes those emotions. The Internet and Higher Education, 15(3), 161-169.

\section{Author Bios}

JOHN JONGHO PARK, PhD, is an Assistant Research Professor in the School of Engineering Design, Technology, and Professional Programs, College of Engineering, Penn State University. His current research interests are in the areas of computational thinking and emotional regulation, intrapreneurial mindset and leadership development, and artificial intelligence education. Email: johnpark2023@utexas.edu

MIHEE PARK, PhD Student, is a Graduate Assistant in the College of Education, Workforce Education and Development, Pennsylvania State University. Her major research interests lie in the area of diversity and organizational development, engineering ethics, intergeneration knowledge transfer, and women in the STEM field. Email: mimipark2023@gmail.com

KATHY L JACKSON, PhD, Adjunct Associate Teaching Professor in the School of Engineering Design, Technology, and Professional Programs, College of Engineering, Penn State University. Her major research areas focus on engineering education, teaching and learning in higher education, faculty development, instructional technologies, and evaluation. Email: klj11@psu.edu

GARRETT VANHOY, $\mathrm{PhD}$, is an Adjunct Lecturer in the Computer Science, Mathematics, and Natural Sciences Department, University of Maryland. As instructor, he has successfully transitioned several engineering laboratory classes into remote learning formats that were part of one of the early ABET-accredited online B.S. Electrical Engineering programs in the U.S offered at University of Arizona. Email: gmvanhoy@gmail.com 